like hospitality to any colleagues in general practice, unless they were his habitual supporters. In fact, what is now a delicate position, which must be left to the good taste and generous motives of those concerned, would be in danger of becoming the source either of scandal or of enforced unsociability. It is one thing for a man with a large consulting practice to make restrictive rules for himself, and 'I think there are cases where both'he and the public may gain thereby; it would be quite another thing for this Association to introduce such arrangements. for the convenience of the practitioner rather than for that of the public, who, indeed, could hardly be expected to tolerate them.

But, after all, what most nearly concerns alike the public and the profession is that consultants, as a class and individually, should possess such real fitness as to be fairly entitled to assume that position with the greatest attain. able advantage to all concerned. Bistinctions we must have in every walk of life, but, to be valuable, they should be the distinctions of endowment, of training, of opportunity, of experience, not such as may be arbitrarily manufactured by the mere "recognition" of an artificial and self.formed group, especially if the "recognition" is to be in the hands, not of a legally constituted medical authority, but of a voluntary Association like ours.

Whatever views we may hold with regard to this and other controversial subjects now agitating the Association, it must, I fear, be admitted on all sides that there are signs of grave dangers confronting us, as a result of the proposed alterations in the Memorandum and Articles of Association. Let us face these dangers fairly, and remember that even if this Association, after a successfal career of over three score years and ten, should be threatened with disaster, the fate of the medical profession is not involved in that of any organization, however great or good. As long as we are faithful to the true objects of our profession, jealous of the purity of its motives, steadily progressive in its practice, and loyal to its honourable traditions, we may be confident that it will continue to command the devotion of its members, and to be of everincreasing value to society.

\section{SOUTH-EASTERN BRANCH.}

FIFTY YEARS OF MEDICAL AND SURGICAL PROGRESS AND THE PART PLAYBD IN IT BY EXPERIMENTAL RESEARCH.

By C. H. ALLFREY, M.D., M.R.C.P., F.R.C.S., D.P.H., Consulting Physician to the East Sussex Hospital, Hastings: and Consulting Physician to the Chislehurst and Cray Valley Hospital.

IT is forty-seven years since I became a member of the Association, joining this Branch when I commenced practice in Kent. That was nearly half a century ago, and it is three years more than the half-century since $I$ com. menced the study of medicine in 1857:

This carries the memory back to the dark ages, as it were, of medicine and surgery. Since that time there has been remarkable progress in both, though, of course, it has been more striking and self.evident in surgery.

It would be difficalt, I think, for a twentieth century stadent to realize the state of surgery in the nineteenth.

The recent introduction of chloroform by Sir James Simpson had no doubt done much to minimize the horrors of an operation and to reduce the anguish, bodily and mental, of the patient and, I may say, of the surgeon as well. Of course, also, the surgeon had no longer to operate against time. But even then, I fancy, that if a capital operation, as performed in those days, could be roproduced, say cinematographically, it would appear to the modern student to be, with all its rough and ready methods, something very nearly akin to butchery. The modern student would hardly realize that it was the fashion for house-surgeons and dressers to carry their needles, sutures and ligatures stuck into and threaded into the front of their coats, the same coats that they wore in the wards and in the post-mortem room. That was the smart thing to do.

It would hardly be an exaggeration to say that it was the exception rather than otherwise for the subject of a capital operation to get well; and then it was generally after a tedious convalescence, during which he ran the gauntlet of the risks of the too frequent complications, such as secondary haemorrhage, erysipelas, hospital gangrene, and pyaemia, which attended the then normal processes of granulation and suppuration, with the copious effusion of what we used to call " laudable" pus. Now all this is changed. It is the exception when a patient dies, and a clean case now runs a rapid and uncomplicated course to recovery, the wound bealing by first intention; more than that, the surgeon now ventures with impunity into regions that he would formerly have approached at his peril. All this we owe to the brilliant researches of Pasteur, and to the genius and keen insight of Lister, who recognized their import, continued the experiments, and applied the principles deduced therefrom for the benefit of humanity.

The progress in the case of medicine may not be so striking and selfevident as in that of surgery; but, especially if we include the important department of preventive medicine, it is probable that at least as many lives have been saved by it to the community, whilst the conditions of life have been improved and the term of natural life has been lengthened by it.

Medicine had, it is true, made a great step at the time of which I am speaking, in that indiscriminate blood. letting and depletion had been given up, though there was danger for a time that it would fall into the opposite error of over.stimulation. Our knowledge had also recently been much extended by Bright's recognition of albumin. uria as connected with disease of the kidneys, followed by the discovery of its grave import from a prognostic point of view. Addison had also pointed out the coincidence of bronzing of the skin with disease of the suprarenal capsules. But even then medicirie was at the best bat a rudimentary and empirical art, and the equipment of the physician was very inferior to what it is now.

We had the stethoscope, but we had no clinical thermometer. The ophthalmic surgeon had the ophthalmoscope, but the physicion had not conceived the possibility of its use for the diagnosis of conditions within the cranium.

$\bar{h}^{\top} \theta$ had, of course, the microscope, of which much use was made, but we had (or at all events used) no higher power than a quarter; we had no immersion lenses, nor any of the modern methods of hardening specimens, making sections, and staining them. We had no laryngoscope, nor any of the various forms of endoscope now in use; and of course we had no $x$ rays and no radium. Electricity was not in general use, and never employed as an aid to diagnosis-for the recognition, for instance, of the reaction of degeneration.

The vaginal speculum had been introduced into practice by Dr. Henry Bennett, but it was thought to be almost improper to use it, and at that time gynaecology had not been established as a distinct department of medicine.

I am not sure, however, that, much as medicine has benefited by all these methods and instruments of precision, the physician may not have lost something. I am not sure that the modern physician, if he will forgive me for saying so, possesses that rapid, intuitive insight into the meaning of symptoms, and that refined sense of touch (tactus eruditus) that his predecessors had, and which they acquired by the necessity of depending upon their own faculties without adventitious aids. For there were, without doubt, "giants in those days."

Our knowledge of medicine is, indeed, very different to what it was fifty years ago. Take, for instance, our knowledge of nervous diseases and the methods employed in their diagnosis-an entirely new field has been opened out. Beyond the recognition of some of the grosser lesions which gave rise to symptoms that we roughly diagnosed as hemiplegia or paraplegia, for instance, and some palpable lesions affecting special nerves, we knew next to nothing about nervous diseases, and our treatment was crade, empirical, and often no doubt erroneous. We recognized, of course, general inflammatory conditions of the brain and spinal cord and their membranes, and, of course, we were familiar with epilepsy as a convulsive disease attended by unconsciousness, but we did not even make a guess at the seat of the mischief in the brain, and by the way, we knew nothing of the use of the bromides in controlling and alleviating the convulsions of epilepsy.

We were taught that the action of potassium bromide 
was similar to that of potassiam jodide, but without its beneficial influence in tertiary syphilis.

I doubt very much whether any of our up-to-date students have ever seen a typical case of rheumatic fever ranning its normal course as we used to see it before Dr. Maclagan initiated the use of salicin and salicylic acid, and their combinations and derivatives were employed in its treatment. Now, although we cannot cure or probably materially shorten the courge of the disease, we are able to control the pyrexia and alleviate the local inflammation and pain at will.

Our knowledge of disease has, of course, been revolu. tionized by the discovery of the part so widely played in its causation by living organisms, which has given us clues to its prevention, relief, or cure. New ground in this fertile field is being continually broken up.

In preventive medicine the advance has been very remarkable. The mortality from consumption has been reduced by at least one half owing to the general improve. ment in sanitary knowledge and to the better understanding of the physiology of health, and more lately owing to the precautions against infection that our newly acquired knowledge of the bacterial origin of the disease has dictated.

Typhus fevar, of which I saw a great deal as a student in London and in Edinburgh, and which was found to be especially favoured by overcrowding and filth, is now practically extinct; whilst cholera, enteric fever, and other waterborne diseases are now, comparatively speaking, under control. Snow had already demonstrated the con. nexion between cholera and impure water, but it was not until many years after that that his conclusions were confirmed by the discovery of the specific bacillus.

The treatment of diphtheria by antitoxin has been very striking in its reduction of the mortality from that disease. No one who has had much experience of that fell disease, both before and aiter the introduction of the antitoxin treatment, can have any doubt as to its favourable influence, and especially when tracheotomy, previously so fatal, has been resorted to. The inoculation treatment of anthrax and hydrophobia proved to be most effective in Pasteur's hands, and, if not yet so successful in enteric fever and plague, is full of promise.

Fraser's work in connexion with snake poisons, con. ducted on similar lines, has been most instructive, although his conclusions have not had quite the practical value that he had hoped, owing to each species of snake having its own venom; but his experiments led him to the valuable discovery of the power of potassium permanganate to oxidize and destroy the poison in them all when promptly and freely employed locally.

Perhaps it is in the case of tropical diseases that the preventive saving of life has been most notable-as, for instance, in the prevention of malaria, yellow fever, and sleeping sickness by the discovery of the peccant organisms, and that these are conveyed to the human subject by insects, such as the mosquito and tsetse $\mathrm{fly}$; and very noteworthy has been the practical extinction of Malta fever among our troops by Bruce's discovery that the organism is conveyed to the human subject by the milk of goats. I cannot do more than refer to the valuable work which is now being energetically prosecuted in the study of immunity, opsonins, and the general use of vaccines (so-called), which, although still in its infancy, promises such a rich harvest.

Now, to what bas this phenomenal advance been due?

There are, of course, more factors than one; but I say without hesitation that none of them alone or conjointly could have availed to any extent had it not been for experimental research as practised on living animals - "vivisection," as its opponents nickname it; but the term is misleading and $I$ shall avoid it. Surgery, as I have already said, owes its present position entirely to Listerian methods. That those methods were the outcome of Lister's experiments on animals we need no farther evidence than that of the master himself. In Lister's evidence before the Royal Commission (1875) he said it had been through experiments on living animals that he "bad been gradually led to the development of his plan of treatment now known as the antiseptic system."

Among the more brilliant of surgical triumphs are the successfal operations on the brain. These would never bave been attempted, even with Listerian precautions, had it not been for the experiments on the brains of monkeys of Frit\&ch, Hitzig, Ferrier, and others, that made diagnosis possible.

It would hardly be correct, perhaps, to say that the discovery of the use of chloroform as an anaesthetic was owing to experiments on animals, unless the story told by Lauder Brunton be true-though he did not vouch for itthat Sir James Simpson's dog accidentally sampled a bottle of chloroform which it had upset, and thus prac. tised an involuntary experiment on itself, of which his master took advantage; but it is certain that we should not have attained to such an accurate knowledge of the properties and action of chloroform on the cardiac and respiratory centres as we now possess had it not been for the more recent experiments on animals. Hence also bas arisen the movement for making special instruction in the administration of anaesthetics obligatory.

As I have eaid, we had no clinical thermometers fifty years ago, nor would they bave been introduced had it not been for $\epsilon$ xperiments that had been made on animal heat. Previously to its introduction the treatment of symptoms now known to be due to hyperpyrexia was haphazard and empirical.

But the whole foundation of modern medicine rests on experimental research; for medicine is based on physio. logy-the "institutes of medicine," as the Scotch call it. Professor Starling, in his evidence before the Royal Commission, eaid: "Practically the whole fabric of physiology is the resultant of experiments on animals." All the textbooks on physiology teem with references to experiments on animals on which their teaching is founded. It will suffice to recall the experiments made by the immortal Harvey, which led up to the discovery of the circulation of the blood, supplemented as they have since been from the time of Hales (with his haemodynamometer) downwards, by experiments which have thrown light on the causes and conditions regulating vasomotor action and arterial tension. The experiments of Sir Charles Bell led up to the location of the centres for respiration and circulation. We owe our knowledge of the function of the spinal and sympathetic system of nerves very much to the experiments of Claude Bernard and Brown-Séquard, and, as I have said, the localization of cerebral function to those of Fritsch, Hitzig, and Ferrier. Working on their foundations, men like Hughlings Jackson and Gowers have opened up the whole wide field of nervous pathology.

Experiments on the action of drugs have been very fruitful; by them many false ideas have been exploded, and useless drugs discarded. For instance, lead, on which we used to rely as our sheet anchor in haemorrhage (though generally given with opium, to which it probably owed its reputation), has now been ohown to be absolutely inert as an arterial constringent.

Digitalis bas been put upon a scientific basis. Formerly it was given empirically as a cardiac sedative, and later as a diuretic. Its true place has now been determined, and, owing to our acquired knowledge as to its action in increasing arterial tension, we have learnt when to avoid it, and to substitute for it a more suitable heart tonic like strophanthus. The action of strophanthus was discovered, in the first instance, accidentally by Fraser, when investigating the properties of the poison of an arrow that had been sent to him. By bis experiments with the poison he was able to establish the value of the drug as a useful remedy in heart disease.

Caffeine has been shown by experiment not to deserve its reputation as a cardiac tonic, and has been relegated to its true position as a valuable diuretic.

It was by experiments on animals that Rutberford and Gamgee discovered the action of amyl nitrite and the nitrites generally in relaxing arterial tension. This led Lauder Brunton to the discovery of its value and that of nitroglscerine for the relief of anginal spasm.

Hosts of new remedies, good, bad, and indifferent, but some of which have come to siay, have been discoveredcoal-tar derivatives and substitution products-like, for instance, antipyrin, acetanilide, and phenacetin, etc.; valuable narcotics like chloral, paraldehyde, sulphonal, veronal, etc., and local anaesthetics like cocaine, eucaine, novocain, stovaine, and which have lately proved to be so valuable in the hands of the surgeon. In every case, 
these drugs, when discovered by the chemist, have had to be tried on animals, their actions ascertained, and their limits of safety determined, as they are all more or less poisonous. It is by such experiments that vegetable drugs have been standardized, for many of our older galenical preparations have been found to vary enormously in strength and even sometimes to be absolutely inert.

The valuable properties of adrenalin as an arterial con. stringent were discovered as the result of Oliver and Schäfer's experiments with suprarenal capsules. Thyroid extract was brought into use for myxoedema and cretinism in the same way. Gull and Ord had, it is true, noticed the coincidence of those conditions with thyroid disease; but it was not until Victor Horsley had made his experiments by the removal of that gland from animals that Murray was able to bring the theory of the treatment by the extract to successful practice.

Now, gentlemen, this is a very sketchy and far from exbaustive outline of the progress of medical science during the past fifty jears, and of the purt played in it by animal research; but it will, I hope, suftice for my parpose, which is to bring home to your minds what a great danger there is that the tide of scientific progress may be set back -in England at least-by the "antivivisection" craze which has taken such a firm hold of the more emotional section of the community. This craze is the outcome of that sentimentality of which Mr. Roosevelt said the other day that "of all broken reeds, it was the most broken reed for righteousness to lean on." Sentimentality is begotten of ignorance, and for jgnorance the only remedy is education. It is no use to attempt to tackle it in any other way, certainly not by entering into acrimonious controversy with personal recriminations, as some of our doughty champions are inclined to do.

I once bad a very gratifying experience of the efficacy of the more peaceful method. I was asked by a young friend to introdace a discussion on vivisection at a working men's club in which he was interested. He told me that I should have a hot time, as the club was a very hotbed of antivivisection views. Well, I girded my loins and went into the fray; but, like David of old, conscious of the strength of my cause, armed only with a sling and a stone. I entered into no controversy; I simply taught my andience the truth, as I have to-day reminded you of it. I won the day, and had the satisfaction of carrying a reso lution to the effect that "experiments on living animals were justifiable" by a unanimous vote. My hearers go up one after the other and said that they had never had the truth of the matter put before them like that before. They were converted to a man. Now, I venture to think that if Sir Victor Horsley-than whom no man living was more qualified to speak from the personal part he had taken in experimental research-had adopted a similar line in his famous duel with the late Bishop Barry at the Folkestone Church Congress, he would have had a signal and a bloodless victory. Instead of that, I am afraid that the discussion rather tended to advertize and popularize the beresy.

The recently formed Research Defence Society will no doubt do much to enlighten the public and I dare say that the great names that are associated with it will carry weight with a certain type of mind.

The most convincing line to take is, I think, to endeavour to make the public realize that the medical advisers, to whom they so readily have recourse when ill and in whose skill they for the most part place such implicit confidence, would be powerless to help them, were it not for knowledge which has been acquired from such experiments as those that they decry. They should be made to realize that in even such a simple and everyday operation as feeling a pulse, their doctor is availing himself of knowledge so gained; as again in the case of the clinical thermometer, of which they make such frequent use as a danger signal. It might even be unkindly suggested to them that they owe theimmunity with which some of them dose themselves with fashionable tabloids and patent preparations, to the experiments on animals by which the safe doses of those often very poisonous drugs have been ascertained.

Now who so well qualified or has such frequent everyday opportunity to undertake this task of education of the public as the trusted family doctor?

It is with this feeling that I have brought the subject before you, the members of this important Branch of our great Association. We can all do our part, and I hope that we shall not fail to take advantage of the opportunity which will soon present itself when the publication of the final report of the Royal Commission again brings the subject prominently before the public. If we do not avail ourselves of it, there is great danger that the agitators may succeed in forcing fresh legislation through Parliament and adding to the already sufficiently restrictive regulations.

\section{WEST SOMERSET BRANCH.}

\section{AFTER TEN YEARS.}

By W. H. MAIDLOW, M.D., F.R.C.S Medical Officer of Health, Ilminster Urban) District.

[ABSTRACT.]

I PROPOSE to address you on those changes, progressings, and decisions which I bave marked, or have been reached by me, after some ten years of general practice.

I venture to think few generations of medical men have lived amidst greater developmental changes than have we who, qualified in the Nineties, have seen the developments of those oft-told stories of antiseptics, anaestbetics, and bacteriology.

I must confess to having made no proper study of the new Poor Law suggestions, but the various tendencies which have brought matters to a head have come to a climax during this period, and it seems to me many of us will live to see the parish medical officer a self-respecting, efficient, and properly paid man merged into some sort of district medical officer, working with the medical officer of health, and a specialist for school clinics ; partly State paid, and partly by a contribution per head at a properly graduated figure. It is possible we may be more heckled and have more reports to write, but very much will depend on our own assertiveness and efficiency. We are bound to justify our existence now more than ever, and face the keen scrutiny which is increasingly brought to bear on our work, like that, indeed, on other workers.

"The new nurse" is at present depriving us of a good deal of work, and of some remuneration, too. She is doing most of the ordinary midwifery; she dresses many cáses, even does a little minor surgery, and thinks she should decide whether a doctor is necessary. She is, in fact, a new order of practitioner. Those of us who like to do our own work rather resent the intrusion of what we consider an insufficiently trained rival, who has had no such expensive education as ourselves, and naturally feel aggrieved. Yet if she can do the work and we are not necessary (and it seems to me her mistakes and disasters are by no means numerous), we shall have to bow to the inevitable and adapt ourselves. The committees consider she is a new order of doctor, and if she refuse to attend without a doctor the subscribers of poorer classes will not pay. If as now existing we are not wanted we shall disappear, and the output of medical men must in some way be made to meet the demand. She, like other things we once considered evil, but now recognize as wholesome fixtures, has come to stay, whether we like it or not. We older ones are rather apt to take the laissez-faire attitude, knowing how night work and rough-and-ready work knocks us up, and we enjoy the increased leisure, which, if we cannot afford now, we never shall.

As regards clubs there is no great alteration to mention. The club member is apt to feel himself slighted and he in return is apt to slight us. He has never considered him. self under the least obligation; and, to my mind, rather reasonably says, "If you do not mean to do your best why did you take on the contract?" The condition is entirely our own fault; we have only to stick together, insist on having a voice in such matters as the position which entitles applicants to admission to clubs, draw up a code detailing what are to be "extras," and insist on some proper fees worked out by some good accountant. Things at present are managed in a slipshod way, and wo muddle along apparently fearing to come to close quarters. I think it probable that if eventually the district medical officer is paid partly by State and partly by capitation contributions, the friendly societies will become some sort of sick insurance arrangement. 